\title{
Complementarity Maps of Wind and Solar Energy Resources for Rio Grande do Sul, Brazil
}

\author{
Gilberto Pianezzola1, Arno Krenzinger ${ }^{1}$, Fausto A. Canales ${ }^{2}$ \\ ${ }^{1}$ Escola de Engenharia, Universidade Federal do Rio Grande do Sul (UFRGS), Porto Alegre, Brazil \\ ${ }^{2}$ Instituto de Pesquisas Hidráulicas (IPH), Universidade Federal do Rio Grande do Sul (UFRGS), Porto Alegre, Brazil \\ Email: fausto.canales.v@gmail.com
}

How to cite this paper: Pianezzola, G. Krenzinger, A. and Canales, F.A. (2017) Complementarity Maps of Wind and Solar Energy Resources for Rio Grande do Sul, Brazil. Energy and Power Engineering, 9, 489-504.

https://doi.org/10.4236/epe.2017.99034

Received: November 20, 2016

Accepted: August 20, 2017

Published: August 23, 2017

Copyright (c) 2017 by authors and Scientific Research Publishing Inc. This work is licensed under the Creative Commons Attribution International License (CC BY 4.0).

http://creativecommons.org/licenses/by/4.0/

\begin{abstract}
If two or more renewable energy sources are available in the same region, their complementary can be advantageous in a hybrid power system. Three indices are defined in this work for assessing the complementarity of solar and wind resources for energy production. Based on existing data of solar radiation and wind speed, these complementarity indices were calculated and represented in the form of maps for the state of Rio Grande do Sul, in southern Brazil. The results found suggest that there are some areas of the state where the use of hybrid wind-solar power systems could be more effective than single photovoltaic or wind systems.
\end{abstract}

\section{Keywords}

Renewable Energy, Complementarity, Energetic Complementarity in Time, Solar Energy, Wind Energy, Hybrid Power Systems

\section{Introduction}

Operational inflexibility is one of the main problems with most renewable or low-carbon technologies for power generation. The power output of these energies usually depends on diurnal and seasonal patterns of the corresponding natural resources used for generating electricity. However, if two or more energy sources exist in the same region, and in significant quantities, this might well justify their complementary use in a hybrid power system.

Referring to energy sources, Beluco et al. [1] defined the term complementarity as the capacity of two (or more) energy sources to present a complementary availability between them. This complementarity may take place in time, in space or both, and it may occur between similar or different types of energy sources. Complementarity is especially important for hybrid power systems, be- 
cause it might influence the capacity and operation regime of the resulting scheme.

The definition of a hybrid power system, for this paper, is similar to the one given by Lukuyu and Cardell [2], a small and often stand-alone system that produces electricity utilizing more than one generating technology, usually involving one or more renewable energy sources and their corresponding storage devices.

There is an increasing interest in assessing complementarity between renewable energy resources. Over the last decade, many authors have worked and written about this subject. Examples of this are the papers by Notton et al. [3], Beluco et al. [4], Denault et al. [5], Li et al. [6], Dihrab and Sopian [7], Hoicka and Rowlands [8] and Monforti et al. [9].

As stated by Hoicka and Rowlands [8] methods and approaches to define and measure complementarity differ according to the system arrangement and optimal solution sought. The present work uses an approach similar to that of Beluco et al. [1], but estimating complementarity between solar and wind energy, instead of solar and hydro. Based on existing data of solar radiation and wind speed, complementarity indices between these two energy sources were calculated and represented in the form of maps for the state of Rio Grande do Sul, in southern Brazil.

The structure of this document is as follows: In Section 2, a definition of the complementarity indices applied and their equations are presented. Section 3 explains the data sources and methods used for estimating solar and wind energy availability, as well as the corresponding equations. In Section 4, the resulting complementarity maps are exhibited and discussed. Finally, the main conclusions from this work are presented on Section 5 .

Representing complementarity through maps is thought to be beneficial, because maps are an adequate form of summarizing, comparing and displaying information in a manner that is easy to understand for most people. This could be useful in the planning stages or in the decision making process for implementing a small hybrid power system.

\section{Complementarity Indices}

In order to explore the complementarity feature of solar and wind energy sources, it is important to know the resources availability regarding their amplitude (minimum and maximum values), average value and behavior along time. Complementarity between solar and wind energy sources can be quantified by means of suitable indices.

Three indices are defined in this work for assessing the complementarity of solar and wind resources for energy production. Their equations and definitions are described in the following subsections.

\subsection{Amplitude Related Partial Complementarity Index}

The Amplitude-related partial complementarity index $i_{a}$, assesses the relation- 
ship between the values of the differences of the maxima to the minima of two energy resources availability functions. Based on the work of Beluco et al. [10], Equations (1) and (2) were adapted for calculating $i_{a}$. in these equations, $\delta_{w}[1]$ is the difference between maximum and minimum value of wind energy availability, $\delta_{\mathrm{s}}[1]$ is the difference between maximum and minimum value of solar energy availability, $E_{w \max }\left[\mathrm{Wh} / \mathrm{m}^{2}\right]$ and $E_{w \min }\left[\mathrm{Wh} / \mathrm{m}^{2}\right]$ are respectively the maximum and minimum values of daily available wind energy through the year, $E_{s \max }$ $\left[\mathrm{Wh} / \mathrm{m}^{2}\right]$ and $E_{s \min }\left[\mathrm{Wh} / \mathrm{m}^{2}\right]$ are respectively the maximum and minimum values of daily available wind energy through the year.

$$
\begin{aligned}
i_{a}= & \frac{1}{2}\left[1-\frac{\left(\delta_{w}-\delta_{s}\right)^{2}}{\left(1-\delta_{s}\right)^{2}}\right]\left\{1-\tanh \left[2^{8}\left(\delta_{w}-\delta_{s}\right)\right]\right\} \\
& +\frac{1}{2}\left[\frac{\left(1-\delta_{s}\right)^{2}}{\left(1-\delta_{s}\right)^{2}+\left(\delta_{w}-\delta_{s}\right)^{2}}\right]\left\{1+\tanh \left[2^{8}\left(\delta_{w}-\delta_{s}\right)\right]\right\} \\
\delta_{w}= & 1+\frac{E_{w \max }-E_{w \min }}{E_{w \max }} \delta_{s}=1+\frac{E_{s \max }-E_{s \min }}{E_{s \max }}
\end{aligned}
$$

It can be easily observed that if the differences $\delta_{w}$ and $\delta_{s}$ are equal, the index $i_{a}$ would be equal to 1 . For this work, a scale factor of 10 will be used, in order to make $i_{a}$ equal to 10 when $\delta_{w}$ and $\delta_{s}$ are equal, and tending to 0 with the increase of their difference.

According to Beluco et al. [1], the index $i_{a}$ was created to account for the difference between maximum and minimum energy availability of the sources in the complementarity evaluation. One energy source cannot be considered for complementarity purposes if it has no available energy during the period of interest. If the two sources present the same energy availability range, they are ideally complementary and the index $i_{a}$ should be equal to 10 . For all intermediate cases, with unequal differences $\delta_{w}$ and $\delta_{s}$, the index $i_{a}$ values will range between 0 and 10 for complementarity less than ideal.

\subsection{Time and Energy Related Partial Complementarity Index}

Two complementarity components are included and combined in the Time- and Energy-related partial complementarity index $i_{e t}$ Beluco et al. [1] explain that Time-related complementarity is used to evaluate the time interval between the minimum availability of the two energy sources. If this interval is exactly half the period, the index will equal to one. If this interval is null, the index will equal to zero. These authors also explicate that the Energy-related complementarity assesses the relationship between the average values of the energy availability functions. If the average values are identical the index should equal to one. If those values are different the index will be smaller, and will tend to zero with the increase of the difference.

Rio Grande do Sul is a subtropical state of Brazil, and because of that, is subject to four seasons a year. Based on that, the Time-related complementarity for 
this work will be considered between seasons (six different combinations). The Equations (3) and (4) are used for calculating $i_{e i}$ In these equations, $E_{w}[1]$ is the weighted wind eneergy, $E_{s}[1]$ is weighted solar eenrgy, $E_{w a v g}\left[\mathrm{Wh} / \mathrm{m}^{2}\right]$ is the average value of daily available wind energy through the year, $E_{\text {savg }}\left[\mathrm{Wh} / \mathrm{m}^{2}\right]$ is the average value of daily available solar energy through the year, $E_{W A}\left[\mathrm{Wh} / \mathrm{m}^{2}\right]$ is the available wind energy through the year, $E_{s A}\left[\mathrm{Wh} / \mathrm{m}^{2}\right]$ is the available wind energy through the year.

$$
\begin{aligned}
& E_{w}=\frac{E_{w \max }-E_{w \min }}{E_{w a v g}} \quad E_{s}=\frac{E_{s \max }-E_{s \min }}{E_{\text {savg }}} \\
& i_{e t}=\frac{E_{s 1}-E_{s 2}}{E_{s A}} \cdot \frac{E_{w 2}-E_{w 1}}{2 \cdot E_{w A}}
\end{aligned}
$$

The 1 and 2 in the subscript indicate the two seasons under consideration (e.g. 1 -spring and 2-fall). As it was the case for the partial complementarity index $i_{a}$, a scale factor of 10 is applied to the index $i_{e t}$ found. Therefore, if $i_{e t}=0$, it means there is no complementarity, in time and energy, of solar and wind energy sources between these two seasons of the year. If $i_{e t}>0$, it represents that there is some complementarity, in time and energy, between these two seasons of the year. When $i_{e t}<0$, it will be assumed that no complementarity takes place. Finally, if $i_{e t}=10$, it implies a maximum complementarity, both in time and energy, of solar and wind energy sources.

\subsection{Total Complementarity Index}

As explained by Beluco et al. [1], the total complementarity index $i_{T}$, indicates the degree of complementarity between two energy sources. It combines the two partial complementarity indices $\left(i_{a}\right.$ and $\left.i_{e t}\right)$ previously described, according to the Equation (5).

$$
i_{T}=i_{a} \cdot i_{e t}
$$

Based on the range of values used in this work for $i_{a}$ and $i_{e b}$ it can be easily observed that the values of $i_{T}$ will be between 0 and 100, with 100 denoting an area with full energetic complementarity.

\section{Data Sources and Methods}

This section presents the data sources used for this paper, as well as the methods employed to process the information available on these, in order to calculate and produce the complementarity maps of solar and wind energy sources for Rio Grande do Sul.

\subsection{Method Used for Extracting Data from Maps Used as Sources}

Colors are used for representing numerical values of geographical features in maps. The digitization of these maps allows using the pixel information, given by the palette, for extracting data that can be combined with other sources for 
compiling new maps using GIS software.

A computer program was developed at the UFRGS Solar Energy Lab to perform the pixel color reading of the maps, by using the getpixel $(x, y)$ function of Visual Basic.NET, which returns the numeric value corresponding to that of the pixel color, by comparing it to a reference palette.

For each nine pixels group was calculated the average of the numeric values associated to them, and then, this average substitutes each individual value.

The computer program starts reading the pixel at the second column of the second row, and continues reading from left to right, every other three pixels, until it finds a pixel with a color defined in the reference palette, and based on this, the average is calculated for this and the other eight surrounding pixels, continuing this process until the end of the row. After this, the reading restarts at the second pixel three rows below, always from left to right, following the same previous method until getting to the last row, according to what is shown in Figure 1 and Figure 2.

When the computer program finds one or more pixels with a color not defined in the reference palette, these are not considered for calculating the corresponding nine pixel group average.

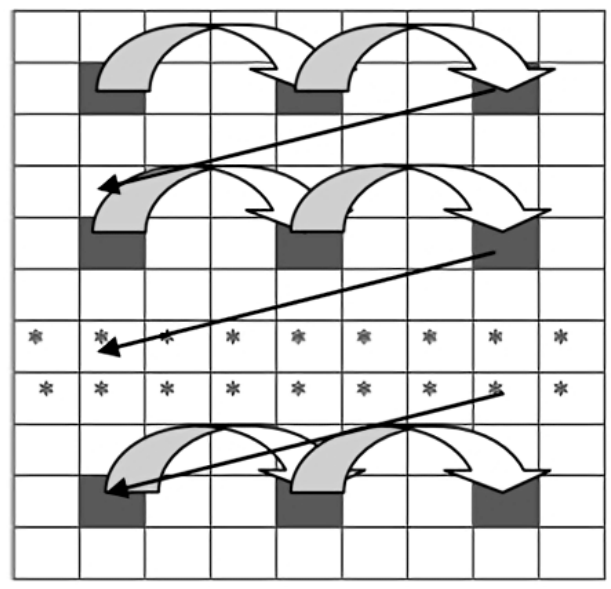

Figure 1. Pixel reading procedure.

\begin{tabular}{|c|c|c|}
\hline$i-1, j-1$ & $i-1, j$ & $i-1, j+1$ \\
\hline$i, j-1$ & $i, j$ & $i, j+1$ \\
\hline$i+1, j-1$ & $i+1, j$ & $i+1, j+1$ \\
\hline
\end{tabular}

Figure 2. Nine pixels group for calculating average values. 


\subsection{Data Sources}

The images used as data sources for this paper, which analyzes complementarity in Rio Grande do Sul, are maps with the average wind speed at 50 meters height, surface roughness and solar radiation on a horizontal surface. It is required to transform wind speed from $50 \mathrm{~m}$ to $10 \mathrm{~m}$ high, in order to use small wind turbines, with lower towers. For a better estimation of available solar energy, a correction is made for calculating the solar radiation on a $45^{\circ}$ sloped surface.

The information related to solar radiation on a horizontal surface for Rio Grande do Sul is taken from the work of Martinazzo [11], and data concerning wind speed at $50 \mathrm{~m}$ and surface roughness from Camargo et al. [12]. The maps from the latter author were digitally modified, so as they match the spatial resolution of the maps from Martinazzo [11].

The computer program explained on the previous subsection was used to extract the information, from these three types of maps, for the average day of the central month of each season.

The resulting images are maps with 254 rows (each encompassing 1'35" of latitude) and 251 columns (each encompassing 1'54" of longitude). The information stored on the cells of these maps can be used in the equations cited in this work.

\subsection{Solar Energy Availability}

Solar radiation data can be available at several different forms, and each one of these can be used for a multiplicity of purposes in the design and development of solar energy systems. Jakhrani et al. [13] explain that monthly total solar radiation on a horizontal surface can be used for designing such systems. However, the process performance is generally not linear with solar radiation, and because of that, the solar radiation measurements on tilted surfaces are essential for more accurate inputs to solar photovoltaic (PV) systems or collectors.

The method used in this work for estimating the solar energy availability (monthly incident solar radiation on a sloped surface) was the isotropic sky model described in Duffie and Beckman [14]. The following values were used:for the southern hemisphere, the slope $\beta=-45^{\circ}$, for Rio Grande do Sul, the latitude $\phi=-30^{\circ}$ and the diffuse reflectance $\rho$ was considered equal to 0.2 .

The value chosen for representing the solar energy availability was considered to be that of the average day of the central month of each season. Table 1 shows the declination $\delta$ and recommended average day for each month.

The declination $\delta$ was found from the approximate equation of Cooper [15], according to Duffie and Beckman [14], shown in Equation (6) where $n$ is the $\mathrm{n}$-th day of the year.

$$
\delta=23.45 \sin \left(360 \cdot \frac{284+n}{365}\right)
$$

The sunset hour angle $\omega_{S}$ is determined by means of Equation (7). 
Table 1. Recommended average days for months and values of $\mathrm{n}$ by months. Source: adapted from: Duffie and Beckman [14].

\begin{tabular}{cccc}
\hline Month & Average day & Declination $(\delta)$ & $n$ \\
\hline January & 17 & -20.9 & 17 \\
February & 16 & -13.0 & 47 \\
March & 16 & -2.4 & 75 \\
April & 15 & 9.4 & 105 \\
May & 15 & 18.8 & 135 \\
June & 11 & 23.1 & 162 \\
July & 17 & 21.2 & 198 \\
August & 16 & 13.5 & 228 \\
September & 15 & 2.2 & 258 \\
October & 15 & -9.6 & 288 \\
November & 14 & -18.9 & 318 \\
December & 10 & -23.0 & 344 \\
\hline & & &
\end{tabular}

The monthly average daily extraterrestrial radiation $H_{o}$, is found using the average day for a particular month, because on that day, the $H_{o}$ value is the closest to the average extraterrestrial radiation value of the month. With solar constant GSC equal to $1367 \mathrm{~W} / \mathrm{m}^{2}$ (adopted by the World Radiation Center), the equations given by Duffie and Beckman [14] for calculating $H_{o}$ is shown in Equation (8). In this equation, $G_{o n}\left[\mathrm{~W} / \mathrm{m}^{2}\right]$ is the extraterrestrial radiation incident on plane normalto radiation.

$$
\begin{aligned}
H_{o} & =G_{o n}\left[\cos \varphi \cos \delta \sin \omega_{S}+\frac{\pi \omega_{S}}{180^{\circ}} \sin \varphi \sin \delta\right] \frac{24 \cdot 3600}{\pi} \\
G_{o n} & =G_{S C}\left[1+0.033 \cos \left(\frac{360 n}{365}\right)\right]
\end{aligned}
$$

Irradiation distribution along the year presents a seasonal trend with daily overlapped fluctuations. For this reason, it is necessary to make this distribution independent of the season, by means of dividing the monthly average daily total radiation on a horizontal surface $H$ by the monthly average daily extraterrestrial radiation $H_{o}$. This results in the monthly average clearness index $K_{b}$ which can be calculated with Equation (10).

$$
K_{t}=\frac{H}{H_{o}}
$$

On a cloudy day, the global radiation on horizontal surfaces received would indicate the diffuse radiation by means of an suitable index, $K_{d}$ correlated to $K_{t}$. The Equation (11) allows estimating the diffuse radiation fraction $K_{\dot{d}}$ : 


$$
K_{d}=\frac{H_{d}}{H}
$$

For $\omega_{\mathrm{S}} \leq 81.4^{\circ}$ and $0.3 \leq K_{t} \leq 0.8$, Duffie and Beckman [14] use the Equation (12) to calculate $K_{d}$ and Equation (13) when $\omega_{S}>81.4^{\circ}$ and $0.3 \leq K_{t} \leq 0.8$.

$$
\begin{aligned}
& \frac{H_{d}}{H}=1.391-3.56 K_{\mathrm{t}}+4,189 K_{t}^{2}-2.137 K_{t}^{3} \\
& \frac{H_{d}}{H}=1.311-3.022 K_{\mathrm{t}}+3.427 K_{t}^{2}-1.821 K_{\mathrm{t}}^{3}
\end{aligned}
$$

The sunset hour angle on a sloped surface, $\omega_{S b}$ is initially found by means of computing the intermediate value $\omega_{S_{2}}$, using the Equation (14).

$$
\omega_{S 2}=\arccos (-\tan (\varphi-\beta) \tan \delta)
$$

Once the $\omega_{S 2}$ value is available, this is compared with $\omega_{S}$. If $\omega_{S}<\omega_{S 2}$, then $\omega_{S t}=$ $\omega_{S 2}$; else $\omega_{S t}=\omega_{S 2}$.

The geometric factor $R_{b}$, which expresses ratio of the average daily beam radiation on the tilted surface to that on a horizontal surface for the corresponding month, can be used to estimate the daily radiation on a sloped surface. For the southern hemisphere, Duffie and Beckman [14] use the Equation (15).

$$
R_{b}=\frac{\cos (\varphi+\beta) \cos \delta \sin \omega_{S t}+\left(\frac{\pi}{180^{\circ}}\right) \omega_{S t} \sin (\varphi+\beta) \sin \delta}{\cos \varphi \cos \delta \sin \omega_{S}+\left(\frac{\pi}{180^{\circ}}\right) \omega_{S} \sin \varphi \sin \delta}
$$

With the features previously found, it is possible to estimate $H_{T}\left[\mathrm{MJ} / \mathrm{m}^{2}\right]$, the monthly average daily radiation on the sloped surface. The expression for calculating $H_{T}$, at the average day of the central month of each season, is available at Duffie and Beckman [14] and shown in Equation (16).

$$
H_{T}=H_{b} R_{b}+H_{d} \frac{(1+\cos \beta)}{2}+H \frac{(1-\cos \beta)}{2} \rho
$$

As mentioned before in a previous section, for this work, the information related to the monthly average daily radiation on a horizontal surface at Rio Grande do Sul can be obtained from Martinazzo [11]. Figure 3 shows the resulting maps with the average daily radiation on the $45^{\circ}$ sloped surface for each season, and Figure 4 displays this average for the year, based on the arithmetic mean of the seasons.

\subsection{Wind Energy Availabiliy}

Like almost every type of energy on the planet, energy coming from the wind is an indirect form of solar energy. The heating of the atmosphere, due to the absorption of solar radiation, combined with the earth's rotation generates global and local wind patterns.

According to Leishman [16], the spatial variation of wind speed with height can be modeled by the logarithmic law, which includes a surface roughness 


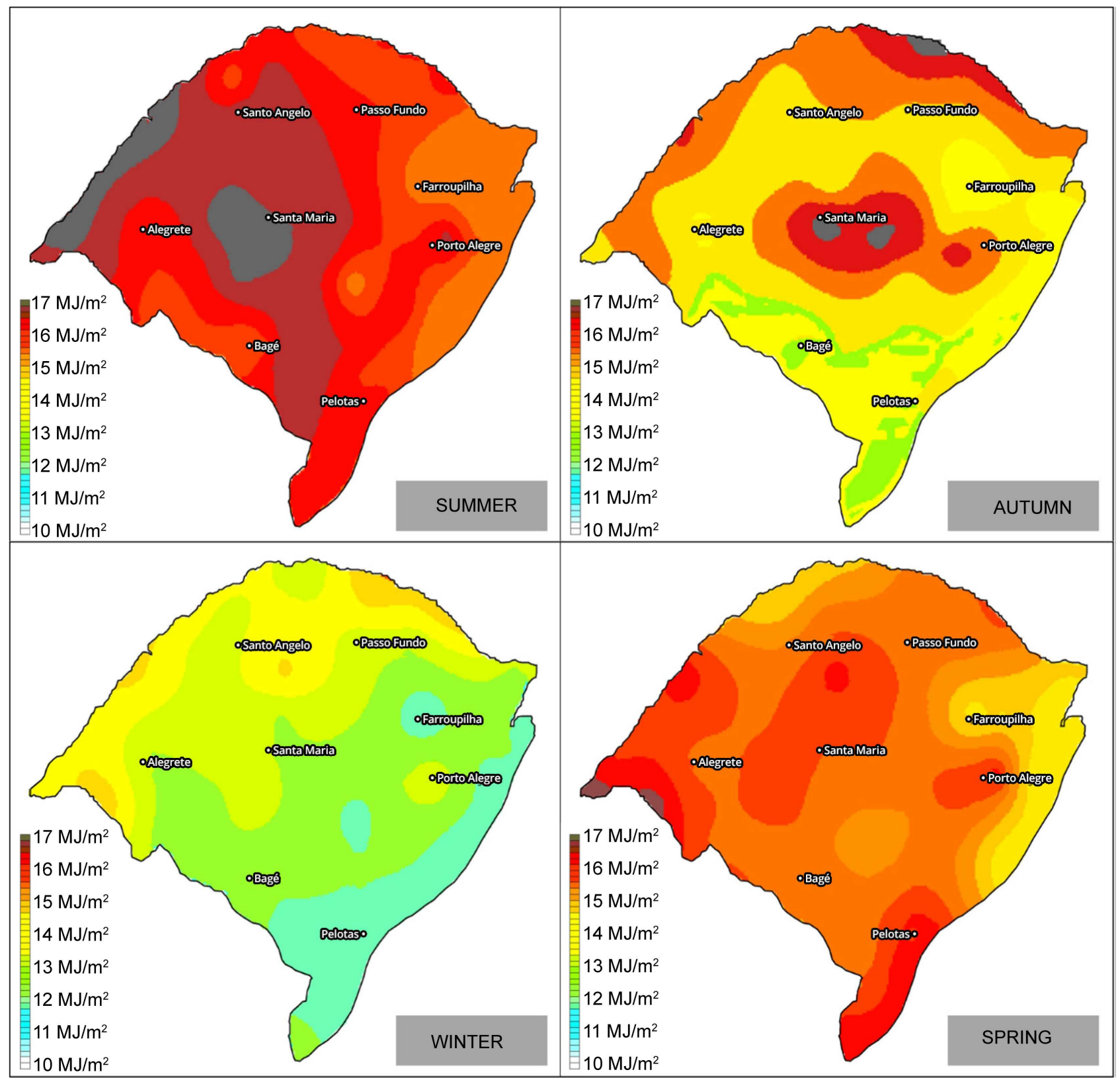

Figure 3. Average daily radiation on $45^{\circ}$ sloped surface for each season in Rio Grande do Sul (RS).

length parameter, $Z_{0}$, representing the effects of the terrain on the upstream boundary layer development. The logarithmic law equation for the time-averaged wind profile is shown in Equation (17), where $V(h)[\mathrm{m} / \mathrm{s}]$ is the wind speed as a funciont of height above ground level $h[\mathrm{~m}], V_{\text {ref }}[\mathrm{m} / \mathrm{s}]$ is the reference wind speed, $h_{\text {ref }}[\mathrm{m}]$ is the reference height and $z_{o}[\mathrm{~m}]$ is the roughness length.

$$
V(h)=V_{\text {ref }} \frac{\ln \left(h / z_{0}\right)}{\ln \left(h_{\text {ref }} / z_{0}\right)}
$$

Table 2 presents some typical surface roughness lengths, as presented by Burton et al. [17]. Something important to highlight is that the logarithmic law 


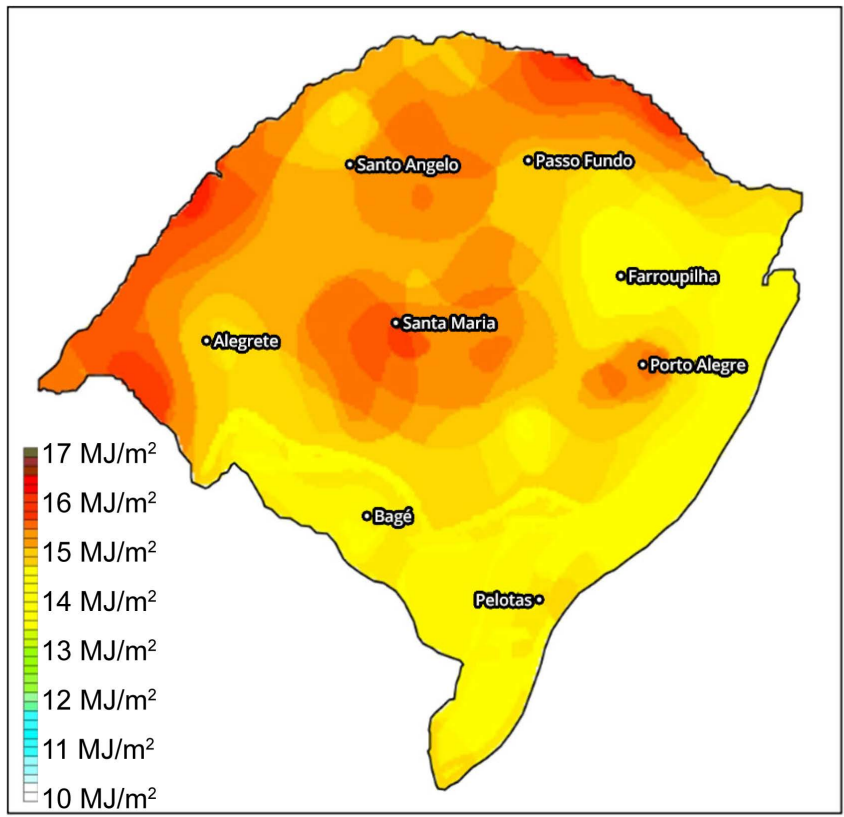

Figure 4. Average daily radiation on $45^{\circ}$ sloped surface per year in RS.

Table 2. Typical surface roughness lengths.Source: Burton et al. (2011).

\begin{tabular}{lc}
\hline Type of Terrain & Roughness length $z_{0}(\mathrm{~m})$ \\
\hline Cities, forests & 0.7 \\
Suburbs, wooded countryside & 0.3 \\
Villages, countryside with trees and hedges & 0.1 \\
Open farmland, few trees and buildings & 0.03 \\
Flat grassy plains & 0.01 \\
Flat desert, rough sea & 0.001 \\
\hline
\end{tabular}

has the limitation of not considering temperature or atmospheric pressure, factors that also have influence on the wind speed.

For this work, wind speed at $10 \mathrm{~m}$ above ground level is estimated based on available wind speed data at $50 \mathrm{~m}$ and surface roughness information, derived from Camargo et al. [12]. Figure 5 shows the resulting maps with the timeaveraged wind profile for each season of the year, and Figure 6 displays this average for the year, obtained from the arithmetic mean of the seasons.

The average power per disk areas wept out by the blades of the wind turbine, $P_{W} / A\left[\mathrm{~W} / \mathrm{m}^{2}\right]$, can be written as shown I Equation (17), where $C_{P}[1]$ is the power coefficient for a wind turbine, $\eta_{C}[1]$ is the mechanical conversion efficiency, $\rho_{\text {air }}\left[\mathrm{kg} / \mathrm{m}^{3}\right]$ is the air density at standard atmospheric conditions, $k_{e}[1]$ is the Weibull shape parameter and $V[\mathrm{~m} / \mathrm{s}]$ is the average wind speed at 10 meters height.

$$
\frac{P_{W}}{A}=\frac{1}{2} C_{P} \eta_{C} \rho_{\text {air }} k_{e} V^{3}
$$




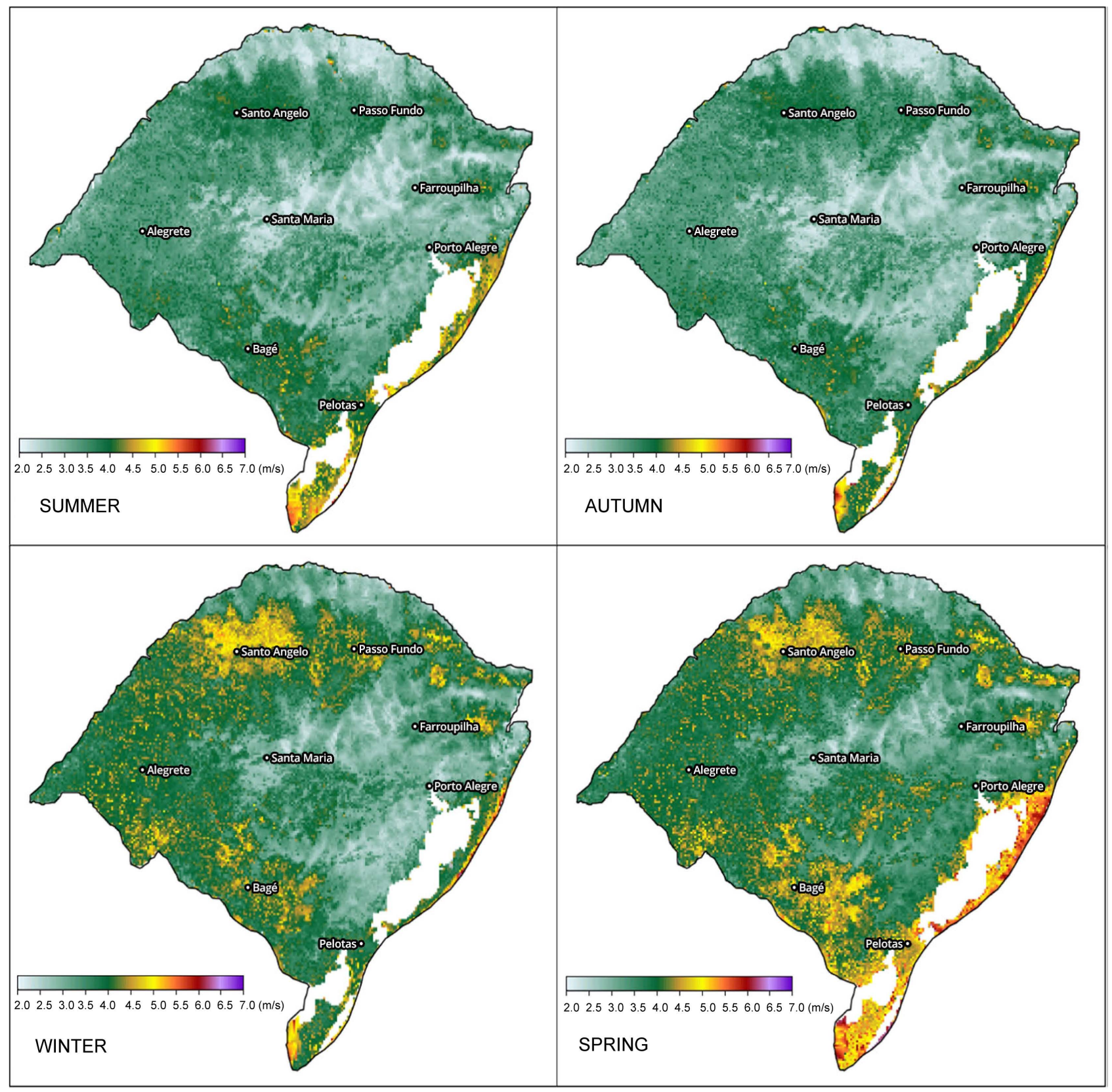

Figure 5. Time-averaged wind profile $10 \mathrm{~m}$ above ground level for each season in RS.

In this work, in order to estimate the average daily wind energy availability derived from the average wind speed at 10meters height, the following values were adopted for these parameters: $C_{P}$ equal to $100 \%, \eta_{C}$ equal to $100 \%, k_{e}$ equal to 2.5 and $\rho_{\text {air }}$ equal to $1.225 \mathrm{~kg} / \mathrm{m}^{3}$.

The value of $100 \%$ assumed for $C_{P}$ and $\eta_{C}$ are obviously not realistic (in fact, the maximum value of $\mathrm{Cp}$ is usually less than $50 \%$ ), but this simplification was made for making the result independent of the wind turbine quality or type. The $k_{e}$ factor of 2.5, uniform for the whole State, was deemed the best fit for the analyzed region. 


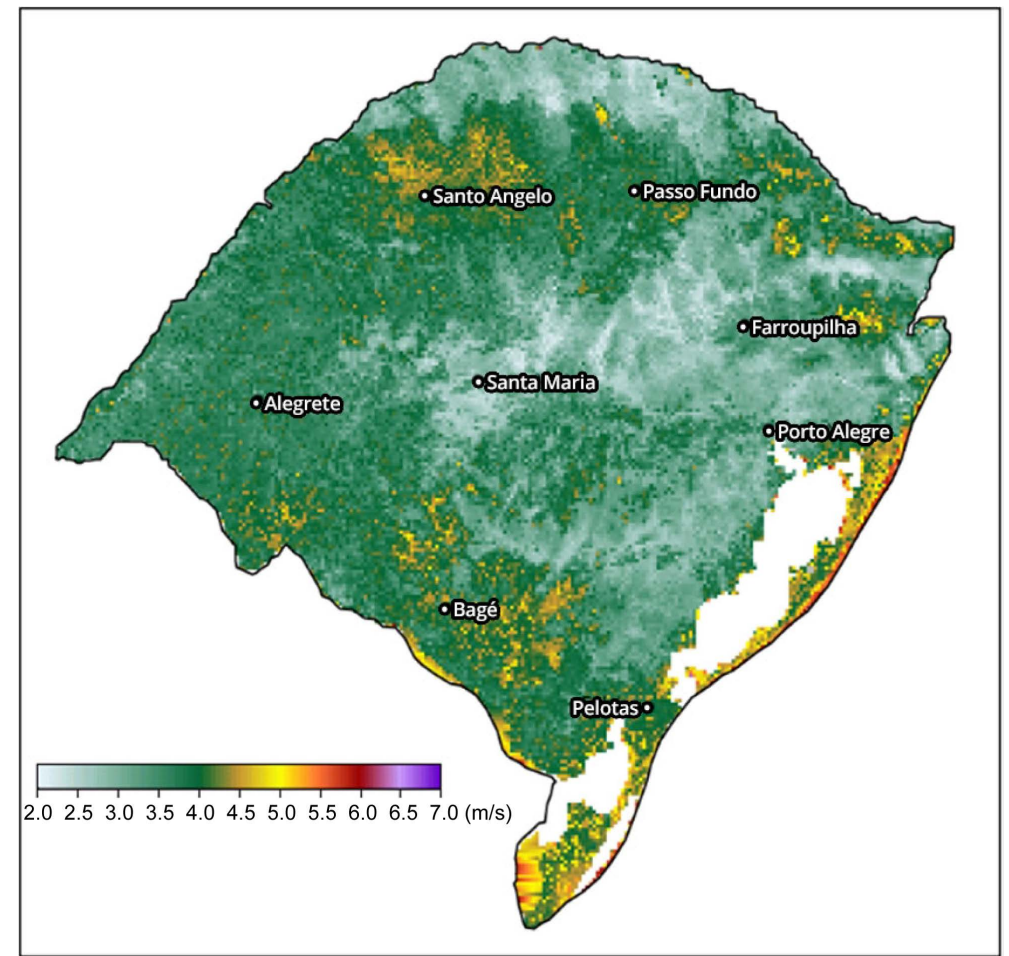

Figure 6. Time-averaged wind profile $10 \mathrm{~m}$ above ground level per year in RS.

\section{Results and Discussion}

Based on the methods and equations described in this paper, the three indices defined in this work for assessing the complementarity of solar and wind resources for energy production were calculated, and the corresponding maps for Rio Grande do Sul were created. These maps are shown in Figure 7, Figure 8 and Figure 9.

Figure 7 depicts the map for amplitude-related partial complementarity index $\left(i_{a}\right)$. It can be observed that in the northern and western regions of the state $i_{a}$ has small values, meaning a fragile complementarity in terms of amplitude. At the south-central part of Rio Grande do Sul, $i_{a}$ presents a range of values indicating the feasibility of using hybrid wind-solar power systems, in terms of the existing amplitude between their minimum and maximum availability along the year. The regions with low $i_{a}$ values could suggest that it would be better to consider only the most promising alternative between wind and solar, instead of planning a hybrid system.

Figure 8 shows the maps for time- and energy-related partial complementarity index $\left(i_{e t}\right)$ between seasons. The lowest values for $i_{e t}$ are found between summer-autumn (Figure 8(e)) and winter-spring (Figure 8(a)), except for a very few regions at the northern and southern extremes of the state. Low $i_{e t}$ values can also be found between autumn-spring (Figure 8(d)), excluding the central part and a strip at the north of the state, but probably not enough to consider using wind-solar hybrid power systems. Similar observations can be made about Figure 8(c) and Figure 8(f). 


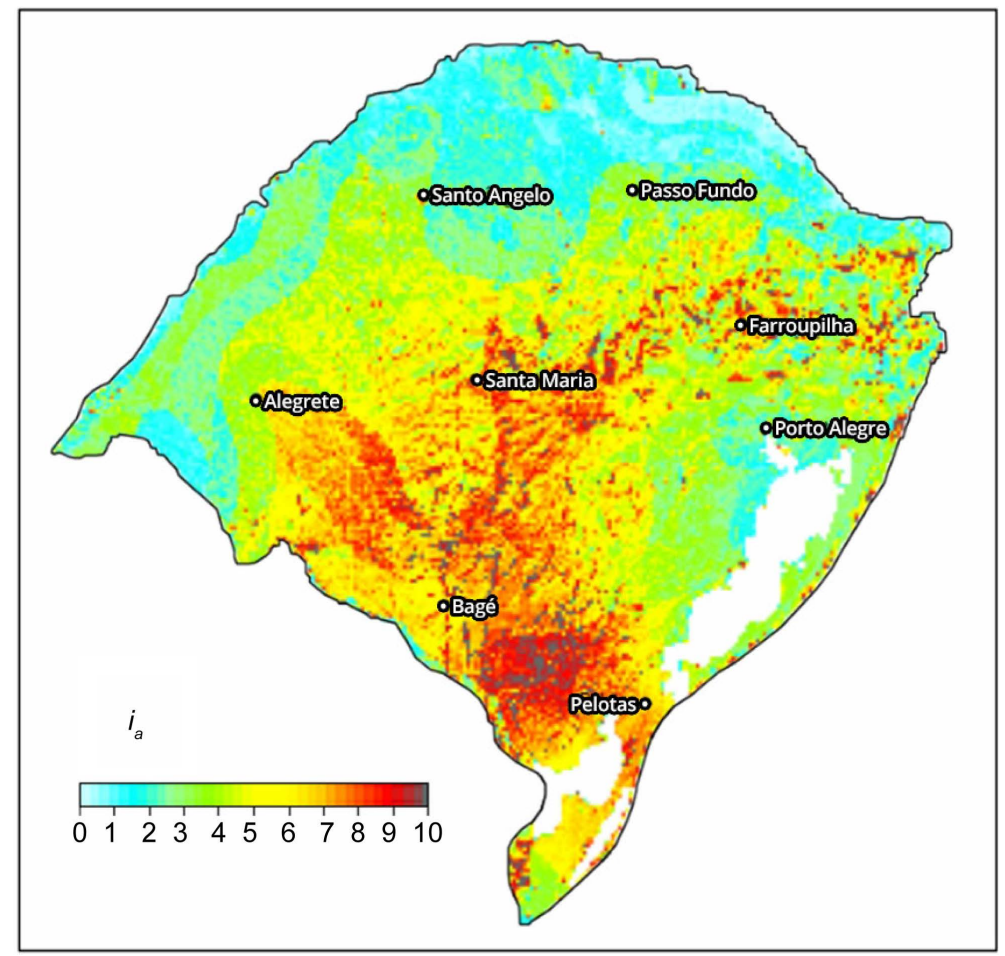

Figure 7. Map for amplitude-related partial complementarity index $\left(i_{a}\right)$.

Figure 8(b) presents the highest $i_{e t}$ values of the six possible combinations between seasons, for winter-summer. With $i_{e t}$ values ranging from 4 to 9 , found at the northern and western parts of Rio Grande do Sul, it is possible to consider these regions for using hybrid wind-solar power systems, accompanying this complementarity map with the evaluation of other technical criteria. For this reason, this map is used, along with Figure 7, for calculating $i_{T^{*}}$ However, it is worth mentioning that there are also parts of the state with low time- and energycomplementarity, especially near Lagoa dos Patos region.

As previously described in this document, the total complementarity index, $i_{T}$, is found by multiplying, together and overlaid, Figure 7 and Figure $8(\mathrm{~b})$. The corresponding map showing $i_{\mathrm{T}}$ values is shown in Figure 9. An interesting area to consider for using hybrid wind-solar power systems is the triangle formed by the cities of Alegrete, Santa Maria and Bagé, with $i_{T}$ values of around 50. By observing the low $i_{T}$ values near Lagoa dos Patos, it can be seen that this region does not present any total complementarity.

\section{Conclusions}

This paper described the main equations, concepts and considerations used for producing complementarity maps of solar and wind energy sources over a region, including the transformation of usually available information, like solar radiation on horizontal surfaces and wind speed at $50 \mathrm{~m}$ above ground level, to solar radiation on sloped surfaces and wind speed at lower heights, in order to improve accuracy. Suitable indices for expressing this complementarity are also 


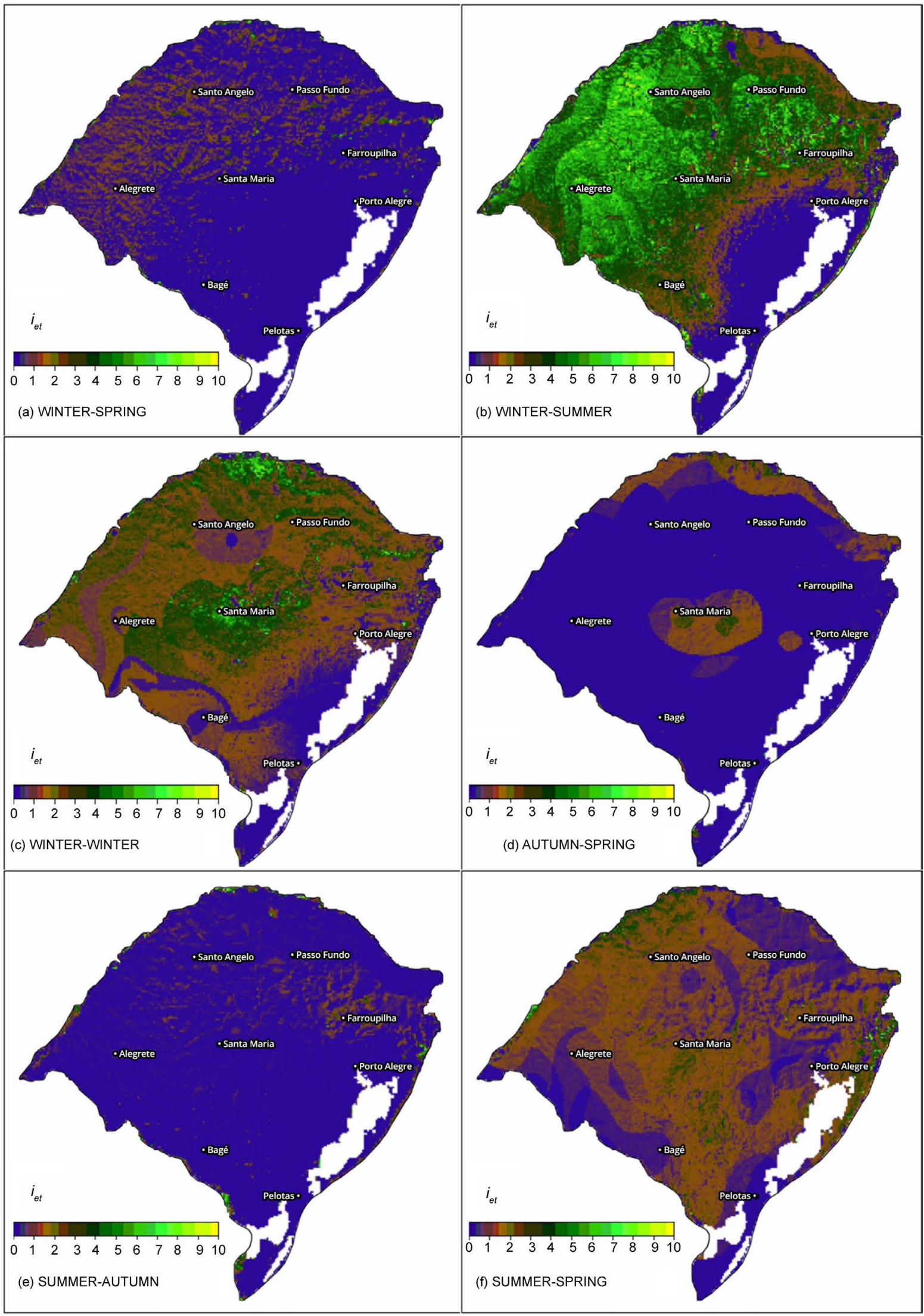

Figure 8. Maps for time- and energy-related partial complementarity index $\left(i_{e t}\right)$ for each season. 


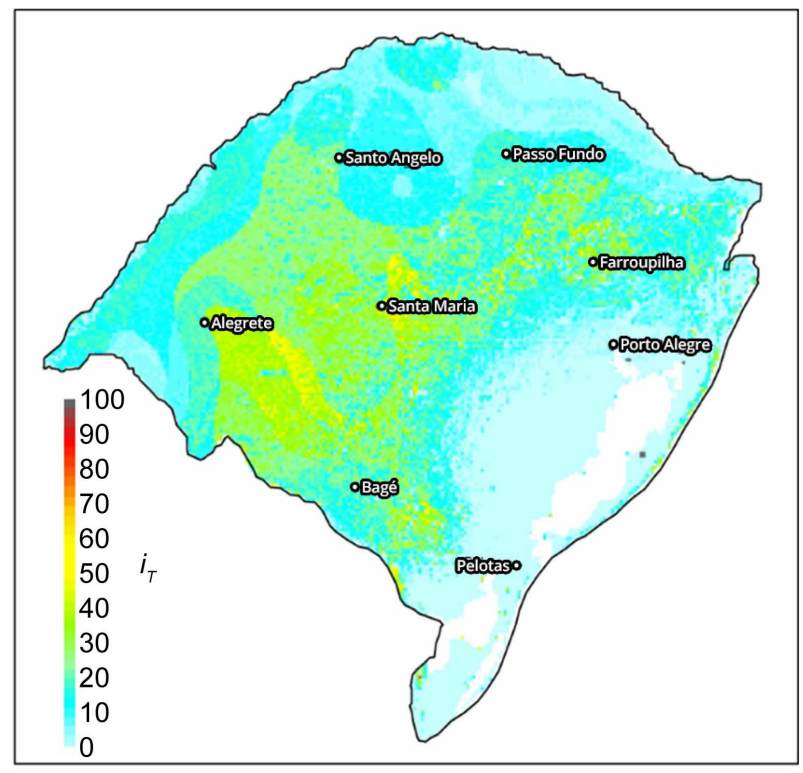

Figure 9. Map for total complementarity index $\left(i_{T}\right)$ of solar and wind energy resources.

explained.

The Rio Grande do Sul State, in southern Brazil, was used as case study to illustrate the methods explained in this work. The corresponding results showed that the greatest existing time- and energy-complementarity, between seasons, is the one for winter-summer. Similarly, the index used to depict this type of complementarity has its lowest values between summer-autumn and winter-spring.

The map showing the amplitude-related partial complementarity index, $i_{a}$, exhibits values along the whole range of options for this index. The lowest values for this complementarity type are found at northern and western regions of the state.

Based on the map displaying the total complementarity index, it can be also concluded that there are regions, in Rio Grande do Sul, where the use of hybrid wind-solar power systems could be more effective than single photovoltaic or wind systems.

Complementarity maps can be used as a tool for a preliminary identification of regions with potential for installing hybrid power systems. Obviously, every important technical, economic and social criteria must be also included in the decision making process and when assessing the sites.

\section{References}

[1] Beluco, A., Souza, P.K. and Krenzinger, A. (2008) A Dimensionless Index Evaluating the Time Complementarity between Solar and Hydraulic Energies. Renewable Energy, 33, 2157-2165. https://doi.org/10.1016/j.renene.2008.01.019

[2] Lukuyu, J.M. and Cardell, J.B. (2014) Hybrid Power System Options for Off-Grid Rural Electrification in Northern Kenya. Smart Grid and Renewable Energy, 5, 89106. https://doi.org/10.4236/sgre.2014.55009

[3] Notton, G., Lazarov, V. and Stoyanov, L. (2008) Complementarity of Solar and 
Wind Sources: Application in Bulgaria and Corsica. In: Sayigh, A., Ed., World Renewable Energy Congress (WRECX).

[4] Beluco, A., Souza, P.K., Livi, F.P. and Caux, J. (2015) Energetic Complementarity with Hydropower and the Possibility of Storage in Batteries and Water Reservoirs. In: Sørensen, B., Ed., Solar Energy Storage, Academic Press, London, 155-188. https://doi.org/10.1016/B978-0-12-409540-3.00007-4

[5] Denault, M., Dupuis, D. and Couture-Cardinal, S. (2009) Complementarity of Hydro and Wind Power: Improving the Risk Profile of Energy Inflows. Energy Policy, 37, 5376-5384. https://doi.org/10.1016/j.enpol.2009.07.064

[6] Li, Y., Agelidis, V.G. and Shrivastaya, Y. (2009) Wind-Solar Resource Complementarity and Its Combined Correlation with Electricity Load Demand. 4th IEEE Conference on Industrial Electronics and Applications, 3623-3628.

[7] Dihrab, S.S. and Sopian, K. (2010) Electricity Generation of Hybrid PV/Wind Systems in Iraq. Renewable Energy, 35, 1303-1307. https://doi.org/10.1016/j.renene.2009.12.010

[8] Hoicka, C.E. and Rowlands, I.H. (2011) Solar and Wind Resource Complementarity: Advancing Options for Renewable Electricity Integration in Ontario, Canada. Renewable Energy, 36, 97-107. https://doi.org/10.1016/j.renene.2010.06.004

[9] Monforti, F., Huld, T., Bodis, K., Vitali, L., D’Isidoro, M. and Lacal-Arantegui, R. (2014) Assessing Complementarity of Wind and Solar Resources for Energy Production in Italy. A Monte Carlo Approach. Renewable Energy, 63, 576-586. https://doi.org/10.1016/j.renene.2013.10.028

[10] Beluco, A., Souza, P.K. and Krenzinger, A. (2003) The Complementarity in Time between Hydro and Solar Photovoltaic Energy Resources. Revista Brasileira de Recursos Hídricos, 8, 99-110. [In Portuguese] https://doi.org/10.21168/rbrh.v8n1.p99-109

[11] Martinazzo, C.A. (2004) Models for Estimation of Solar Radiation to Build Solarimetric Maps. Master Dissertation, Mechanical Engineering, Universidade Federal do Rio rande do Sul (UFRGS), Porto Alegre. [In Portuguese]

[12] Camargo, O.A., Silva, F.J.L., Custodio, R.S. and Graviono, N. (2002) Wind Atlas: Rio Grande do Sul. Secretaria de Energia, Minas e Comunicações, Porto Alegre/RS. 70 p. [In Portuguese]

[13] Jakhrani, A.Q., Othman, A.K., Rigit, A.R., Samo, S.R. and Kamboh, S.A. (2012) Estimation of Incident Solar Radiation on Tilted Surface by Different Empirical Models. International Journal of Scientific and Research Publications, 2, 1-6.

[14] Duffie, J.A. and Beckman, W.A. (2013) Solar Engineering of Thermal Processes. 4th Edition, John Wiley \& Sons, New York. https://doi.org/10.1002/9781118671603

[15] Cooper, P.I. (1969) The Absorption of Solar Radiation in Solar Stills. Solar Energy, 12, 333-346. https://doi.org/10.1016/0038-092X(69)90047-4

[16] Leishman, J.G. (2011) Aerodynamics of Horizontal Axis Wind Turbines. In: Mathew, S. and Philip, G.S., Eds., Advances in Wind Energy and Conversion Technology, Springer, Berlin. https://doi.org/10.1007/978-3-540-88258-9_1

[17] Burton, T., Jenkins, N., Sharpe, D. and Bossanyi, E. (2011) Wind Energy Handbook. 2nd Edition, John Wiley \& Sons, New York. https://doi.org/10.1002/9781119992714 
Submit or recommend next manuscript to SCIRP and we will provide best service for you:

Accepting pre-submission inquiries through Email, Facebook, LinkedIn, Twitter, etc. A wide selection of journals (inclusive of 9 subjects, more than 200 journals)

Providing 24-hour high-quality service

User-friendly online submission system

Fair and swift peer-review system

Efficient typesetting and proofreading procedure

Display of the result of downloads and visits, as well as the number of cited articles Maximum dissemination of your research work

Submit your manuscript at: http://papersubmission.scirp.org/

Or contact epe@scirp.org 